\section{Ocular morbidity associated with intravitreal triamcinolone acetonide}

\begin{abstract}
Aim To report on the complications associated with the use of intravitreal triamcinolone acetonide (IVTA) in a tertiary referral hospital setting.

Materials and methods A retrospective case series review of all IVTA injections carried out over a period of 30 months.

Results One hundred and thirty IVTA injections were performed; nine with limited local follow-up were excluded. Thus, 121 injections (108 patients, 114 eyes) were included in the study. Triamcinolone $(4 \mathrm{mg})$ was used in all cases. Indications were diabetic macular oedema ( $n=41$ eyes), retinal vein occlusions $(n=27)$, postoperative cystoid macular oedema $(n=24)$, exudative age-related macular degeneration $(n=16)$, and others $(n=6)$. No intraoperative complications were recorded. Postoperative intraocular pressure (IOP) readings of $22,28,35$, and $40 \mathrm{mmHg}$ or higher were recorded in 46.5, 29.8, 12.3, and $7.9 \%$ of eyes, respectively. IOP elevation was treated with antiglaucoma medication in all but one eye $(0.9 \%)$ that required trabeculectomy and one $(0.9 \%)$ that required vitrectomy with cataract extraction for suspected phacoanaphylactic glaucoma. Two eyes $\mathbf{( 1 . 8 \% )}$ developed retinal detachment; both had previously been treated for retinal breaks. One eye $(0.9 \%)$ developed culture-positive endophthalmitis. Conclusions Significant morbidity is associated with IVTA injection; clinicians should be aware when considering treatment options.
\end{abstract}

Eye (2007) 21, 317-320. doi:10.1038/sj.eye.6702416; published online 19 May 2006

Keywords: intravitreal triamcinolone; complications; intraocular pressure
A Konstantopoulos, CPR Williams, RS Newsom and AJ Luff

\section{Introduction}

Intravitreal triamcinolone acetonide (IVTA) is used to treat ocular conditions associated with macular oedema, such as diffuse diabetic macular oedema, retinal vein occlusion, exudative age-related macular degeneration, and noninfective uveitis. ${ }^{1-4}$ In the past few years, there has been a remarkable interest in its use. This is demonstrated by an increasing number of publications; Pubmed search of 'intravitreal triamcinolone' resulted in 145 publications during the year 2005 compared to 81 during 2004 and 50 for the year before. In this study, we report on the complications associated with its use in a tertiary referral hospital setting.

\section{Materials and methods}

We carried out a retrospective case series review of all IVTA injections carried out between August 2002 and December 2004 at Southampton Eye Unit, England. One hundred and thirty procedures were carried out, but nine that had limited or no follow-up were excluded. Thus, 121 procedures were included in this study.

Patients underwent baseline examination, including Snellen visual acuity, slit-lamp biomicroscopy, Goldmann tonometry, and dilated fundus examination. The IVTA injections were carried out under aseptic conditions in theatre. Triamcinolone acetonide $4 \mathrm{mg}$ in $0.1 \mathrm{ml}$ (Kenalog, Bristol-Meyers Squibb, Middlesex, UK) was injected pars plana, 3.0 and $3.5 \mathrm{~mm}$ behind the limbus for pseudophakic and phakic individuals, respectively. Topical antibiotics (g. chloramphenicol or oc. chloramphenicol) were used for 1 week to the treated eye. All patients were asked to attend outpatient review initially at $2-4$ weeks post-
Southampton Eye Unit, Southampton University Hospitals NHS Trust, Southampton, Hampshire, UK

Correspondence:

A Konstantopoulos, Southampton Eye Unit, Southampton University Hospitals NHS Trust,

Tremona Road,

Southampton, Hampshire SO16 6YD, UK Tel: + 4407843694175 , + 4402380798742 ;

Fax: + 4402380777222 .

E-mail: ariskons@yahoo.com

Received: 16 January 2006 Accepted in revised form: 2 April 2006 Published online: 19 May 2006

Part of the paper accepted as abstract at Annual Congress of Royal College of Ophthalmologists 2006

No proprietary interest or funding involved 
treatment and then at 6-8 weeks. Subsequent reviews were scheduled for 3-5 months and then 6-8 months post-treatment, unless earlier review was required. Patients experiencing pain or decreased vision were advised to attend before their booked appointment. Elevated intraocular pressure (IOP) and other complications were treated at the discretion of the clinician.

In this study, a pressure response was defined as a postoperative IOP of $22 \mathrm{mmHg}$ or higher. Two-tailed paired $t$-test was used for comparison of parametric data.

\section{Results}

One hundred and fourteen eyes of 108 patients were included in the study. Forty-seven patients (43.5\%) were women and 61 men (56.5\%). Mean age was 67.7 years (SD 12.4, range 28-94, median 69). Mean IOP before the procedure was $16.1 \mathrm{mmHg}$ (SD 2.7, range 10-25, median 16). Two eyes had mild ocular hypertension (OHT) requiring no treatment. Six eyes had glaucoma; that is, three primary open angle (POAG), one pseudoexfoliation, one narrow angle, and one rubeotic glaucoma. All glaucoma eyes had IOP less than $21 \mathrm{mmHg}$ before treatment.

The indications for IVTA injection were diabetic macular oedema ( $n=41$ eyes), retinal vein occlusion $(n=27)$, postoperative cystoid macular oedema $(n=24)$, macular oedema associated with age-related macular degeneration $(n=16)$, and other causes of macular oedema $(n=6)$.

No intraoperative complications were recorded. Mean IOP increased significantly $(P<0.001)$ from $16.1 \mathrm{mmHg}$ before treatment to a mean maximum of $24.3 \mathrm{mmHg}$ (SD 10.5 , range 11-70, median 21) postoperatively. At first, second, and third reviews mean IOP remained significantly higher $(P<0.001)$ than before treatment (Table 1). At the last review (6-8 months), mean IOP was not significantly different $(P=0.07)$ to baseline. Figure 1 shows the total percentage of eyes that had shown increased IOP by each review. By the last review, an IOP of 22,25 , and $28 \mathrm{mmHg}$ or higher had been recorded in

Table 1 Intraocular pressure (IOP) before and after intravitreal injection $4 \mathrm{mg}$ triamcinolone

\begin{tabular}{lrcc}
\hline & $\begin{array}{c}\text { Number of } \\
\text { eyes }\end{array}$ & $\begin{array}{c}\text { IOP }(\mathrm{SD}) \\
{[\mathrm{mmHg}]}\end{array}$ & P value \\
\hline Before treatment & 114 & $16.1(2.5)$ & \\
Review 1: 2-4 weeks & 94 & $21.0(7.5)$ & $<0.001$ \\
Review 2: 6-8 weeks & 85 & $21.4(9.4)$ & $<0.001$ \\
Review 3: 3-5 months & 67 & $20.7(7.1)$ & $<0.001$ \\
Review 4: 6-8 months & 48 & $18.7(9.3)$ & 0.07 \\
\hline
\end{tabular}

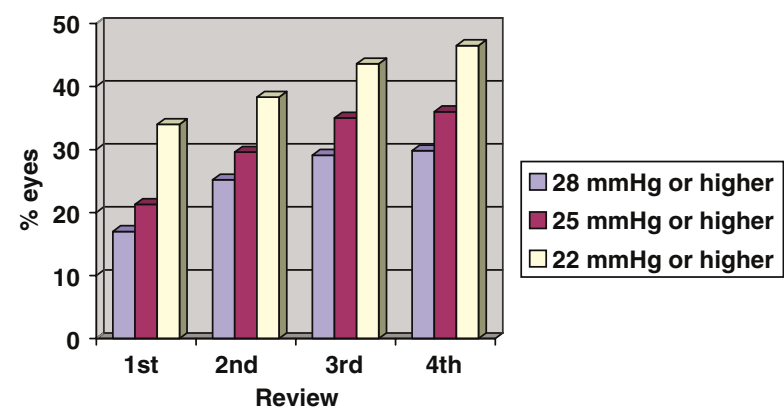

Figure 1 Total of eyes with elevated intraocular pressure of each review.

$46.5,35.9$, and $29.8 \%$ of eyes, respectively. Overall, $12.3 \%$ of eyes had maximum IOP $35 \mathrm{mmHg}$ or higher and $7.9 \%$ $40 \mathrm{mmHg}$ or higher. Mean maximum IOP in the eyes that showed a pressure response was $32.2 \mathrm{mmHg}$ (SD 10.2, range $22-70$, median 29$)$. The majority of eyes $(82 \%)$ developed a pressure response within the first 2 months following the procedure; three eyes developed high IOP at the $6-8$ month review with readings of 23,24 , and $46 \mathrm{mmHg}$.

In the group of patients with pre-existing glaucoma, one of the three eyes with POAG developed IOP of $31 \mathrm{mmHg}$ but settled on one additional topical agent; the other two did not show a pressure response. The eyes with narrow angle, pseudoexfoliation, and rubeotic glaucoma showed a pressure response all with maximum IOP of $32 \mathrm{mmHg}$, but also settled on one additional topical agent. One of the two eyes with OHT developed IOP of $28 \mathrm{mmHg}$ that resolved on one topical treatment, the other did not show a pressure response.

Six patients had bilateral IVTA injections at different sittings. Two patients developed a pressure response in both eyes, two patients in one eye and two patients in neither eye. Seven patients who had IVTA injections repeated to the same eye did not show a pressure response.

Thirty-nine of the 53 eyes that developed a pressure response were treated with topical agents. Two-third of eyes (67\%) required one topical agent, $23 \%$ two agents, and $10 \%$ three or more agents. Despite treatment, two eyes $(1.8 \%)$ developed glaucomatous optic neuropathy, one requiring mitomycin-enhanced trabeculectomy. In addition, one eye $(0.9 \%)$ developed an IOP of $62 \mathrm{mmHg}$ at the 6-8 week review. This was attributed to phacoanaphylactic glaucoma that was treated successfully with vitrectomy and cataract extraction.

One eye $(0.9 \%)$ developed culture-positive endophthalmitis; coagulase-negative staphylococcus was grown on vitreous tap. Two eyes (1.8\%) developed a retinal detachment in the postoperative period. Both had pre-existing retinal pathology; one had been treated for a 
retinal tear and the other for endophthalmitis and retinal detachment.

\section{Discussion}

Systemic and topical corticosteroids have been used to treat a range of ophthalmic conditions, including giant cell arteritis, uveitis, and Graves' orbitopathy. ${ }^{5-7}$ They have an anti-inflammatory action by inhibiting prostaglandin and leukotriene production, and by eliciting apoptosis in inflammatory cells such as T-lymphocytes. ${ }^{8,9}$ The exact mechanism of action of triamcinolone, concerning reduction of macular oedema, remains uncertain. Intravitreal steroids have been shown to stabilise the blood-retinal barrier after retinal photocoagulation and to reduce the vitreous cavity concentration of vascular endothelial growth factor. ${ }^{10,11}$ Corticosteroids have traditionally been used with a degree of caution owing to the well-known side effects. ${ }^{12}$ Intravitreal triamcinolone has also been associated with side effects such as raised IOP, cataract formation, and endophthalmitis. ${ }^{13-16}$

The most commonly reported complication associated with IVTA injection is elevation of IOP. ${ }^{17-19}$ The rate of this complication shows wide variation in published studies ranging from 20.8 to $52 \%$ of operated eyes. ${ }^{18,13}$ The dose of triamcinolone acetonide injected into the vitreous also varies from 4 to $25 \mathrm{mg}$ and this may potentially affect the rate and level of IOP elevation. ${ }^{2,13}$ In our series, a large proportion $(46.5 \%)$ of injected eyes developed a pressure response, despite the use of a low dose $(4 \mathrm{mg})$. The largest study on IOP elevation associated with IVTA quotes a response rate of $41.2 \%$ with the use of $20 \mathrm{mg}$ triamcinolone. ${ }^{19}$ Our study suggests that using a lower dose does not appear to affect the incidence of IOP elevation following the procedure.

A considerable proportion of eyes developed very high IOP; $12.3 \%$ of eyes developed an IOP of $35 \mathrm{mmHg}$ or higher and $7.9 \%$ an IOP of $40 \mathrm{mmHg}$ or higher. Kok et al, also using $4 \mathrm{mg}$ triamcinolone, found similar levels of IOP elevation; $34 \%$ of eyes developed IOP of $30 \mathrm{mmHg}$ or higher and $11 \%$ an IOP of $40 \mathrm{mmHg}$ or higher. This contrasts with Jonas et al, ${ }^{19}$ who showed that only $5.5 \%$ of patients had an IOP above $35 \mathrm{mmHg}$ and $1.8 \%$ above $40 \mathrm{mmHg}$. Interestingly, Jonas used a higher dose of triamcinolone $(20 \mathrm{mg})$. In line with published data, one of our patients' eyes $(0.9 \%)$ required filtration surgery. ${ }^{13,18,19}$ In total, two eyes in our series developed glaucomatous optic neuropathy and a third required cataract extraction and vitrectomy for suspected phacoanaphylactic glaucoma. These results highlight the fact that IOP elevation following IVTA injection may be potentially serious.
In the group of eight patients with pre-existing glaucoma and OHT, five eyes $(62.5 \%)$ showed a pressure response following the procedure. This rate appears to be higher than the average of the study, but owing to the small number of patients it is difficult to comment on its significance. Most studies have similarly found a higher rate of IOP response in patients with pre-existing glaucoma. Ozkiris and Erkilic ${ }^{18}$ found that $70.6 \%$ of 17 eyes with POAG showed a response compared to $14.2 \%$ of eyes with normal IOP before treatment. Jonas et $a l^{13}$ found that $66.6 \%$ of the six patients with POAG showed a pressure response compared to $48.6 \%$ of the remaining patients. In our study, the maximum postinjection IOP in these patients ranged from 28 to $32 \mathrm{mmHg}$ and required the addition of only one topical pressure-lowering agent. However, in patients with pre-existing glaucomatous optic neuropathy, this may accelerate loss of retinal ganglion cells and visual field. In view of the fact that the IOP may increase at any point up to 6-8 months after the IVTA injection, we recommend that patients with preexisting optic neuropathy be monitored closely.

One patient $(0.9 \%$ eyes) presented 6 days postprocedure with endophthalmitis, which was confirmed on vitreous tap with growth of coagulase-negative staphylococcus. Despite initial intravitreal antibiotics and subsequent vitrectomy combined with further intravitreal antibiotics, the patient developed rubeotic glaucoma; final visual acuity was perception of light. This patient was diabetic and developed endophthalmitis on his second (repeat) IVTA injection to the same eye. Noninsulin-dependent diabetes has been identified as a potential risk factor for endophthalmitis following IVTA injection. ${ }^{16}$ Bacterial endophthalmitis following IVTA injection is uncommon; Westfall et $a l^{20}$ reported no cases of culture-positive endophthalmitis in 1006 consecutive procedures, whereas Moshfeghi et al ${ }^{16}$ quoted a rate of $0.87 \%$ in a series of 922 IVTA injections.

Two patients developed a rhegmatogenous retinal detachment in the postinjection period. One patient was treated for cystoid macular oedema that developed following extensive argon laser retinopexy for a large horseshoe-shaped tear. The second patient required IVTA for cystoid macular oedema following vitrectomy with cryotherapy and argon laser retinopexy for a retinal detachment that occurred following cataract extraction endophthalmitis. Although retinal detachment has not been reported as a complication of IVTA injection, it is a well-known complication associated with posterior segment procedures. ${ }^{21}$ This is particularly true for eyes with pre-existing retinal pathology. In patients with AIDS and cytomegalovirus retinitis, for example, ganciclovir implant procedure is associated with a retinal detachment rate of $5 \% .^{22}$ The two cases in our series are 
most likely owing to pre-existing retinal breaks rather than direct retinal trauma during the procedure. However, any intravitreal injection does carry a potential risk of retinal detachment, regardless of the underlying pathology.

Our study highlights the significant morbidity associated with IVTA injections. The procedure is associated with a low risk of intraoperative complications. However, IOP elevation following the procedure is common and further surgery may occasionally be required for satisfactory control. A small risk of retinal detachment also exists following the procedure, albeit in our study only seen in eyes with pre-existing retinal pathology. Fortunately, endophthalmitis, a potentially devastating complication, is not common. The clinician should be aware of these potential problems when discussing treatment options with the patient.

\section{References}

1 Jonas JB, Kreissig I, Sofker A, Degenring RF. Intravitreal injection of triamcinolone for diffuse diabetic macular oedema. Arch Ophthalmol 2003; 121: 57-61.

2 Ip MS, Gottlieb JL, Kahana A, Scott IU, Altaweel MM, Blodi BA et al. Intravitreal triamcinolone for treatment of macular oedema associated with central retinal vein occlusion. Arch Ophthalmol 2004; 122: 1131-1136.

3 Jonas JB, Kreissig I, Hugger P, Sauder G, Panda-Jonas S, Degenring R. Intravitreal triamcinolone acetonide for exudative age related macular degeneration. $\mathrm{Br} \mathrm{J}$ Ophthalmol 2003; 87: 462-468.

4 Kok H, Lau C, Maycock N, McCluskey P, Lightman S. Outcome of intravitreal triamcinolone in uveitis. Ophthalmology 2005; 112: 1916-1921.

5 Chan CCK, Paine M, O'Day J. Steroid management in giant cell arteritis. Br J Ophthalmol 2001; 85: 1061-1064.

6 McCluskey PJ, Towler HM, Lightman S. Management of chronic uveitis. BMJ 2000; 320: 555-558.

7 Ebner R, Devoto MH, Weil D, Bordaberry M, Mir C, Martinez $\mathrm{H}$ et al. Treatment of thyroid associated ophthalmopathy with periocular injections of triamcinolone. Br J Ophthalmol 2004; 88: 1380-1386.

8 Hood PP, Cotter TP, Costello JF, Sampson AP. Effect of intravenous corticosteroid on ex-vivo leukotriene generation by blood leucocytes of normal and asthmatic patients. Thorax 1999; 54: 1075-1082.

9 Compton MM, Cidlowski JA. Rapid in vivo effects of glucocorticoids on the integrity of rat lymphocyte genomic deoxyribonucleic acid. Endocrinology 1986; 118: 38-45.
10 de Wilson CA, Berkowitz BA, Sato Y, Ando N, Handa JT, de Juan Jr E. Treatment with intravitreal steroid reduces blood-retinal barrier breakdown due to retinal photocoagulation. Arch Ophthalmol 1992; 110: 1155-1159.

11 Brooks Jr HL, Caballero Jr S, Newell CK, Steinmetz RL, Watson D, Segol MS et al. Vitreous levels of vascular endothelial growth factor and stromal-derived factor 1 in patients with diabetic retinopathy and cystoid macular oedema before and after intraocular injection of triamcinolone. Arch Ophthalmol 2004; 122: 1801-1808.

12 Stanbury RM, Graham EM. Systemic corticosteroid therapy - side effects and their management. $\mathrm{Br} \mathrm{J}$ Ophthalmol 1998; 82: 704-708.

13 Jonas JB, Kreissig I, Degenring R. Intraocular pressure after intravitreal injection of triamcinolone acetonide. $\mathrm{Br} J$ Ophthalmol 2003; 87: 24-27.

14 Gillies MC, Kuzniarz M, Craig J, Ball M, Luo W, Simpson JM. Intravitreal triamcinolone induced elevated intraocular pressure is associated with the development of posterior subcapsular cataract. Ophthalmology 2005; 112: 139-143.

15 Moshfeghi DM, Kaiser PK, Bakri SJ, Kaiser RS, Maturi RK, Sears JE et al. Presumed sterile endophthalmitis following intravitreal triamcinolone acetonide injection. Ophthalmic Surg Lasers Imag 2005; 36: 24-29.

16 Moshfeghi DM, Kaiser PK, Scott IU, Sears JE, Benz M, Sinesterra JP et al. Acute endophthalmitis following intravitreal triamcinolone acetonide injection. Am J Ophthalmol 2003; 136: 791-796.

17 Ciardella AP, Klancnik J, Schiff W, Barile G, Langton K, Chang $S$. Intravitreal triamcinolone for the treatment of refractory diabetic macular oedema with hard exudates: an optical coherence tomography study. Br J Ophthalmol 2004; 88: 1131-1136.

18 Ozkiris A, Erkilic K. Complications of intravitreal injection of triamcinolone acetonide. Can J Ophthalmol 2005; 40: 63-68.

19 Jonas JB, Degenring RF, Kreissig I, Akkoyun I, Kammppeter BA. Intraocular pressure elevation after intravitreal triamcinolone acetonide injection. Ophthalmology 2005; 112: 593-598.

20 Westfall AC, Osborn A, Kuhl D, Benz MS, Mieler WF, Holz ER. Acute endophthalmitis incidence: intravitreal triamcinolone. Arch Ophthalmol 2005; 123: 1075-1077.

21 Michels RG, Wilkinson CP, Rice TA. Other causes of retinal detachment. In: Michels RG, Wilkinson CP, Rice TA (eds). Retinal Detachment. St Louis: The C.V Mosby Company, 1990, Chapter 4, pp 194-195.

22 Lim JI, Wolitz RA, Dowling AH, Bloom HR, Irvine AR, Schwartz DM. Visual and anatomical outcomes associated with posterior segment complications after ganciclovir implant procedures in patients with AIDS and cytomegalovirus retinitis. Am J Ophthalmol 1999; 127: 288-293. 